\title{
CONTEXTUALIZAÇÃO E INTERDICIPLINARIDADE NUM CURSO DE LICENCIATURA EM FÍSICA: UMA EXPERIÊNCIA VIVENCIADA NO IFCE CAMPUS SOBRAL
}

\author{
Antônio Nunes de Oliveira ${ }^{1}$, Marcos Cirineu Aguiar Siqueira ${ }^{1}$, Rodrigo Martins Lima $^{1}$ \\ ${ }^{1}$ Instituto Federal de Educação, Ciência e Tecnologia do Ceará - IFCE \\ <profantuness@gmail.com><mcirineu@gmail.com><profantuness@gmail.com> \\ DOI: <https://doi.org/10.21439/10.21439/conexoes.v14i4.1522>
}

\begin{abstract}
Resumo. É notória a importância da contextualização e da interdisciplinaridade durante as aulas de Física, sendo elas do nível básico ou superior. Embora sejam comprovadamente duas vertentes do ensino capazes de potencializar a participação do aluno na aula e ajudar na sua interação com o professor, propostas com esse perfil ainda são insuficientes para prover as necessidades educacionais contemporâneas. Este texto resulta de uma pesquisa qualitativa e exploratória onde se narra experiências planejadas para produzir conhecimento pedagógico, concretizada com o auxílio de questionários, e que relata uma experiência vivenciada na qual se evidenciam as potencialidades de aulas contextualizadas e do diálogo entre as áreas do conhecimento que integram a matriz curricular de um curso de licenciatura em Física. Nas aulas ora em destaque procurou-se promover um ambiente interdisciplinar, o que possibilitou aos graduandos perceberem a importância das disciplinas do currículo para uma compreensão mais geral dos fenômenos, e ainda entrelaçar a sua explicação ao modelamento matemático necessário à compreensão e interpretação de dados brutos, bem como às aplicações e repercussões no contexto social, político, econômico, cultural, ético e ambiental. Além disso, os resultados evidenciaram claramente a problemática da obrigatoriedade dos sábados letivos como forma de reposição das aulas perdidas por conta de um período de greve na instituição considerada, podendo este vir a ser, em tal contexto, um fator responsável por parcela significativa da evasão e retenção discente.
\end{abstract}

Palavras-chaves: Contextualização, Interdisciplinaridade, Ensino de Física, Sábados Letivos.

\begin{abstract}
The importance of contextualization and interdisciplinarity during physics classes is noteworthy, being they of the basic level or the higher one. Although they are two strends of teaching provenly capable of enhancing student participation in class and helping in their interaction with the teacher, proposals with this profile are still insufficient to meet contemporary educational needs. This text is the result of a qualitative and exploratory research that narrates experiences planned to produce pedagogical knowledge, materialized with the help of questionnaires, and which reports a lived experience in which the potentialities of contextualized classes and the dialogue between the areas of knowledge that integrate the curricular matrix of a degree course in Physics are evidenced. In the classes in focus, the aim was to promote an interdisciplinary environment, that made it possible for undergraduates to understand the importance of curriculum subjects for a more general understanding of the phenomena, and to interweave their explanation to the mathematical modeling necessary to understand and interpret raw data, as well as to the applications and repercussions in the social, political, economic, cultural, ethical and environmental context. In addition, the results clearly showed the problem of compulsory lessons on Saturdays as a way of replacing lost lessons due to a strike period in the concerned institution, which could be, in such context, a factor responsible for a significant portion of dropout and students' retention.
\end{abstract}

Keywords: Contextualization, Interdisciplinarity, Physics Teaching, Saturday Classes. 


\section{INTRODUÇÃO}

A pesquisa aqui em destaque foi realizada em um dos campi do Instituto Federal de Educação, Ciências e Tecnologia do Ceará (IFCE) durante os sábados letivos de um Curso de Licenciatura em Física (CLF), ao longo do semestre 2017.1. Sua intenção é relatar a experiência do uso da contextualização e da interdisciplinaridade na abordagem de temas tratados sob a ótica de professores de áreas distintas cujas abordagens se complementam à medida que os conteúdos se comunicam. Além disso, pretende-se expor a problemática envolvida na obrigatoriedade de reposição de aulas do período de greve, em dias de sábado, no âmbito institucional.

No IFCE, o sábado letivo é uma orientação das notas técnicas $\mathrm{n}^{\circ} 11$ de $2015, \mathrm{n}^{\circ} 19$ de 2016 e do Ofício Circular $n^{\circ} 2$ de 2016, que emitem recomendações a serem respeitadas pelos campi durante a elaboração do calendário acadêmico, visando à reposição de aulas referentes à greve que ocorreu em 2015 (IFCE, 2015. IFCE, 2016; BRASIL, 2016b). A perspectiva é que o calendário institucional seja regularizado no semestre 2018.2.

Os sábados letivos em foco aconteceram nos dias 01 e 08 de julho de 2017 e no dia 05 de agosto do mesmo ano. As temáticas para as aulas surgiram a partir do diálogo entre os docentes do curso de Licenciatura em Física, motivados pela necessidade de incentivar os alunos a participarem das atividades letivas referentes aos dias em questão. As experiências anteriores com aulas aos sábados possibilitaram a constatação da dificuldade de reunir professores e alunos em atividades de ensino e aprendizagem durante esses dias. Uma das maiores dificuldades diz respeito à distância física entre a cidade de moradia de cada um deles e o local de trabalho/estudo. Dos 12 (doze) professores do núcleo de licenciaturas apenas 5 (cinco) fixaram residência na cidade onde está situada a instituição de ensino em questão. Os demais residem na capital, a aproximadamente $250 \mathrm{~km}$. O CLF conta com 141 alunos regularmente matriculados, dos quais cerca de $70 \%$ residem em outras cidades cuja distância ao campus varia de 16,2 km (cidade mais próxima) a 145,4 km (cidade mais distante).

Foi pensando em superar esse tipo de problema e engajar os discentes e docentes do CLF em atividades de ensino durante os finais de semana, que se chegou às temáticas do Tabela 1 as quais, na visão do grupo de professores, possibilitariam reunir várias turmas em aulas coletivas capazes de favorecer uma discussão da Ciência que fosse contextualizada e ao mesmo tempo interdisciplinar.

No Tabela 1 estão descritos os sábados que foram letivos para o CLF no semestre 2017.1, os temas escolhidos para as aulas desses dias e sua duração. Podemos observar nele que, no primeiro e no último dia, as aulas possuíram cada uma a carga horária de quatro horas, enquanto que no segundo dia ela constou de oito horas de duração. A justificativa para essa diferença deve-se à temática escolhida a qual, por sua complexidade e conteúdo, exigiu maior tempo.

Contextualizar o conteúdo ensinado em sala de aula é uma ideia presente no discurso dos professores e educadores, especialmente quando se trata do ensino de Física, uma disciplina que oferece explicações para os fenômenos naturais, cuja ocorrência é algo comum para os alunos, assim como a busca por respostas. Para $\mathrm{Ri}-$ cardo (2010):

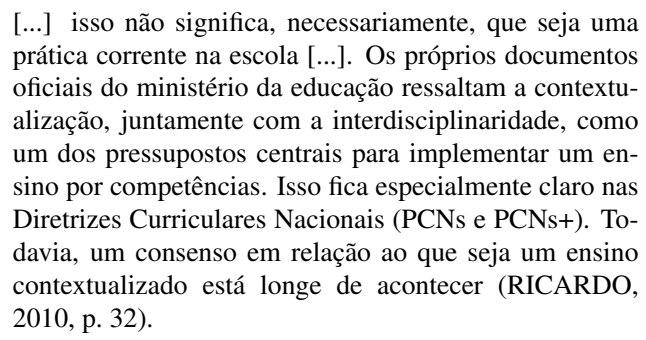

Ainda segundo (RICARDO, 2010, p. 32), “[...] é bastante comum, entretanto, associar a contextualização com o cotidiano dos alunos e seu entorno físico [...]". Nessa perspectiva, contextualizar o conteúdo ensinado é uma forma que os professores têm utilizado para motivar a aprendizagem, uma ideia que tem sido reforçada pelas próprias Diretrizes Curriculares Nacionais para o Ensino Médio (DCNEM) e compartilhada por autores como Zen e Pereira (2013):

\footnotetext{
O cenário atual para o ensino de Física é de muitas dificuldades, principalmente com relação às dificuldades de aprendizagem nas aulas de Física e a prática pedagógica do professor. Um fator que pode ajudar em ambas as dificuldades é a contextualização do conteúdo, aproximando os conceitos físicos abordados em sala de aula com o cotidiano dos alunos. O professor, ao incorporar uma prática pedagógica que contemple essa contextualização pode conseguir resgatar o interesse dos alunos pela Física assim como também ajudar na aprendizagem deles (ZEN; PEREIRA 2013 p. 3).
}

Para Santos (2007), é preciso ter em mente que a contextualização não é nenhuma vara mágica por si só ela não é capaz de resolver os problemas da educação, embora abordagens contextualizadas cumpram um importante papel no ensino à medida que possuem o potencial de envolver os educandos.

Assim, a contextualização pode ser vista com os seguintes objetivos: 1) desenvolver atitudes e valores em uma 
CONTEXTUALIZAÇÃO E INTERDICIPLINARIDADE NUM CURSO DE LICENCIATURA EM FÍSICA: UMA EXPERIÊNCIA VIVENCIADA NO IFCE CAMPUS SOBRAL

Tabela 1: Temáticas abordadas nos sábados letivos de um Curso de Licenciatura em Física do IFCE durante o semestre 2017.1.

\begin{tabular}{|c|c|c|}
\hline DIA LETIVO & TEMÁTICA DA AULA & HORAS- AULA \\
\hline $01 / 07 / 17$ & $\begin{array}{c}\text { Radioatividade, vida e obra de Maria Curie e a mina } \\
\text { de urânio de Itataia em Santa Quitéria }\end{array}$ & $04 \mathrm{~h} / \mathrm{a}$ \\
\hline $08 / 07 / 17$ & Osciladores Harmônicos e Aplicações & $08 \mathrm{~h} / \mathrm{a}$ \\
\hline $05 / 08 / 17$ & $\begin{array}{c}\text { Visita monitorada a Casa do Capitão-Mor e ao museu MADI } \\
\text { (Movimento, Abstração, Dimensão e Inclusão), em Sobral/CE. }\end{array}$ & $04 \mathrm{~h} / \mathrm{a}$ \\
\hline
\end{tabular}

Fonte: Créditos dos autores

perspectiva humanística diante das questões sociais relativas à ciência e à tecnologia; 2) auxiliar na aprendizagem de conceitos científicos e de aspectos relativos à natureza da ciência; e 3) encorajar os alunos a relacionar suas experiências escolares em ciências com problemas do cotidiano (SANTOS 2007, p. 5).

Para Ricardo (2010), faz-se necessário questionar a pertinência do que é ensinado na escola tendo em vista as exigências do mundo moderno. Isso se torna evidente no Ensino de Ciências de um modo geral, em especial, no Ensino da Física. Segundo ele, “[...] ao mesmo tempo em que os alunos convivem com acontecimentos sociais significativos estreitamente relacionados com as Ciências e a Tecnologia e seus produtos, recebem na escola um Ensino de Ciências que se mostra distante dos debates atuais [... ]" (RICARDO, 2010 p. 29). Tendo em vista a discussão acerca de um Ensino de Física consistente com tais discussões, cabe uma investigação sobre quais conteúdos são mais significativos dentro de cada realidade.

No Ceará, a extração de urânio da mina de Itataia, localizada na cidade de Santa Quitéria, que fica a 221 $\mathrm{km}$ da capital do estado, Fortaleza, indica um forte motivo para a abordagem do conteúdo Radioatividade durante a formação de professores, e entende-se que uma possível omissão no tratamento desse assunto causaria uma deficiência formativa significativa capaz de repercutir nas práticas do nível básico, pois, de acordo com Carvalho e Gil-Pérez (2011), os professores costumam reproduzir aspectos de sua formação pessoal, isto é, se durante o seu itinerário escolar e acadêmico eles experimentaram predominantemente um ensino descontextualizado e com ausência de interdisciplinaridade, certamente irão repetir as práticas vivenciadas por eles com seus alunos.

O Projeto Santa Quitéria divide opiniões na mídia regional há muitos anos e tem importância crucial para o futuro da região. Ele foi idealizado originalmente no sentido de explorar Urânio para abastecer as usinas de Angra dos Reis e previa, em 2014, quando o primeiro estudo de impacto ambiental recebeu o aceite do
IBAMA, um investimento de 860 milhões de reais. Em entrevista ao Jornal O Estado, o coordenador do projeto falava na criação de 900 empregos diretos e 2200 indiretos, no incremento na economia da região e na prevenção do êxodo de jovens durante os períodos de seca (LOPES, 2014), mas o grande problema que alimenta as discussões até hoje é o problema do lixo radioativo e da escassez hídrica na região. Naquela época, o consórcio responsável pela usina planejava construir uma adutora de $53 \mathrm{~km}$ de extensão para transportar água do açude Edson Queiroz até a mina, o que suscitou a oposição das comunidades afetadas e até mesmo a mobilização da Igreja no sentido de impugnar o empreendimento (LOPES, 2014). Adiada muitas vezes, a implementação do projeto agora está prevista, segundo reportagem do Jornal O POVO, para 2020, e deverão ser produzidas, também, 800 mil toneladas/ano de matériaprima para fertilizantes (FERNANDES; NASTACIO, 2017).

Esse contexto regional torna bastante favorável a abordagem do tema Radioatividade numa perspectiva contextualizada e interdisciplinar. Segundo Almeida et al. (2005, p. 32), “[...] a interdisciplinaridade consiste na prática da interação entre os componentes do currículo e é um processo que se desenvolve de acordo com as necessidades específicas de cada contexto [...]". Mais que isso: para Fazenda (2008) a interdisciplinaridade compreende diálogos entre pares, capazes de entender a mensagem das diferentes línguas em suas entrelinhas e, na prática, ela busca a troca de ideias locais e sua universalização.

\footnotetext{
Se definirmos interdisciplinaridade como junção de disciplinas, cabe pensar currículo apenas na formatação de sua grade. Porém se definirmos interdisciplinaridade como atitude de ousadia e busca frente ao conhecimento, cabe pensar aspectos que envolvem a cultura do lugar onde se formam professores (FAZENDA 2008 p. 17).
}

Um tratamento interdisciplinar de assuntos de interesse imediato dos envolvidos certamente os levará a desenvolver outras competências que não sejam apenas 
aquelas da área da Física. Ao se produzir um incentivo para que disciplinas distintas trabalhem em cooperação para melhoria do ensino e aprendizagem, estamos colaborando com a formação de um cidadão mais ativo, crítico e participativo na sociedade.

Para Grillo e Perez (2016, p. 65), “[...] a interdisciplinaridade é hoje reconhecida como sendo de grande importância e necessidade [...]" e Cohn ${ }^{1}$ (2006), citado por Grillo e Perez (2016, p. 65), afirma que "[...] todo trabalho científico de real importância transcende os limites disciplinares e também a capacidade de trabalho de um pensador isolado [...]".

Em vista do que foi exposto, é importante que o professor, durante o seu processo formativo, vivencie um ensino contextualizado e interdisciplinar para que ele possa, enquanto educador, oportunizar uma formação aos educandos que esteja em harmonia com as necessidades formativas deles.

\section{METODOLOGIA}

A pesquisa realizada constitui-se numa narrativa de experiências planejadas para produzir conhecimento pedagógico, já que foi elaborada com o intuito prévio de pôr a teste os paradigmas científicos contextualização e interdisciplinaridade na resolução de um problema refratário que afeta as aulas ministradas nos sábados letivos do IFCE e que se expõe de duas formas conexas: na ausência sistemática de muitos dos alunos nos encontros, e na desmotivação dos que se fazem presentes, a ponto de não participarem das atividades propostas de forma efetiva. Para compreender melhor acerca da experiência particular de cada aluno com esse tipo de proposta, até então inédita no campus considerado, é que se optou pelo uso de questionários semiestruturados enquanto instrumentos de pesquisa, os quais foram interpretados levando sempre em consideração os motivos, significados e valores próprios da comunidade local.

Para a concretização das aulas optou-se por temáticas propositadamente diversificadas, tal como disposto no Tabela 1. O assunto escolhido para abordar em 01 de julho de 2017 envolveu a discussão contextualizada da extração de Urânio em Santa Quitéria-CE, uma cidade que, segundo o censo do IBGE de 2016 (BRASIL 2016a) , possui uma população de 42.763 habitantes.

Devido ao seu poder radioativo, o Urânio é conhecido pelo grande potencial energético assim como os males que pode causar ao ser humano se não for ma-

${ }^{1} \mathrm{COHN}, \mathrm{G}$. Interdisciplinaridade é fundamental para pensar os novos dilemas do planeta. Jornal da Ciência, 21 de julho de 2006. nipulado adequadamente. Se por um lado seu potencial energético atraiu grandes investidores para a região, com o objetivo de explorar a mina de fosfato-uranita, por outro lado, o perigo de rejeitos radioativos deixou toda a comunidade em alerta.

Pires e Messeder (2017) apontam para a necessidade de abordagem do conteúdo Radioatividade na Educação Básica. Para eles, na ótica dos documentos oficiais, a intenção é abordar esse assunto de forma a possibilitar aos alunos reconhecer o fenômeno da Radioatividade na natureza e tomar consciência do seu domínio por parte da ciência e suas potencialidades na agricultura, medicina e na geração de energia. Além disso, percebe-se que o tema pode ser trabalhado de forma interdisciplinar entre a Física, a Química e a Biologia. Entre outras coisas pode-se estabelecer relações com o meio ambiente e esclarecer quanto ao impacto da radiação em sistemas biológicos.

Tendo em vista um tratamento contextualizado do tema, planejou-se a apresentação de duas palestras intituladas: Marie Curie: vida e obra, e A Extração de Urânio em Santa Quitéria, as quais seriam apresentadas pelos alunos e monitores da disciplina de Metodologia do Ensino de Física (MEF) e, durante a exposição, os docentes realizariam intervenções motivando discussões de forma a favorecer uma abordagem interdisciplinar com a participação de todos.

Para o dia 08 de julho foi escolhida pelo grupo uma temática presente em disciplinas específicas do curso, Osciladores Harmônicos e Aplicações, mas que se aplica em diferentes ramos da Física e em outras áreas do conhecimento como: na Biologia, para descrever a interação entre bactérias e vírus bacteriófagos, como em Lenski (1988); na Biofísica, para descrever a potência mecânica envolvida na locomoção humana, conforme Romeo (2009); na Economia, como inspiração para reinterpretar a teoria do crescimento econômico, em Salamaga (2013) e na Cosmologia, para descrever o comportamento ao longo do tempo do ínflaton, um campo escalar que modula a aceleração e desaceleração do universo, como descreve Linde (2000).

Para ministrar essa aula foi convidado um docente externo à instituição, especialista em Física Aplicada. A proposta da aula almejava além de fortalecer a formação dos alunos em disciplinas específicas do curso, enfatizar a importância da Matemática no currículo da Física, uma vez que a compreensão dos fenômenos físicos geralmente passa pelo seu modelamento matemático e, além disso, mostrar através de aplicações das oscilações, que a Ciência não é um conjunto de conhecimentos fragmentados, como a propósito, discorre Chi- 
quetto (2011) ao mencionar a forma como nosso currículo organiza os conteúdos, mas sim composta de áreas de estudos que se entrelaçam, se complementam e que os avanços na compreensão de determinada área estão intimamente ligados aos de outras.

E finalmente, para concluir as atividades dos sábados letivos do semestre em questão, optou-se por realizar uma visita monitorada ao museu MADI (Movimento, Abstração, Dimensão e Inclusão) e à Casa do Capitão-Mor, em Sobral-CE, durante a qual os professores discutiriam aspectos científicos, históricos e culturais relativos aos pontos visitados, com a possibilidade de entrelaçamento entre eles. Dentro desse contexto, a presença dos pesquisadores no grupo se demonstrou de suma importância para a apreensão dos progressos que, de fato, foram realizados em meio à atividade em curso, conforme defende Lima, Geraldi e Geraldi (2015, p. 19): "A aproximação entre pesquisador e pesquisado, longe de ser um mecanismo de 'contaminação' da pesquisa, significa a possibilidade de construção de outras compreensões acerca das nossas experiências."

A fim de verificar as percepções dos envolvidos, planejou-se a coleta de dados mediante a aplicação de três questionários semiestruturados, um para cada aula. O momento de aplicação deveria coincidir com a conclusão de cada etapa e as perguntas tencionavam sondar dos alunos suas percepções acerca das temáticas envolvidas, das potencialidades do tipo de abordagem para a sua motivação, perceber suas visões acerca da interação proporcionada entre os discentes e docentes do CLF, além de oportunizar um espaço para que eles manifestassem suas principais dificuldades de acesso e participação nas atividades propostas.

\section{RESULTADOS E DISCUSSÕES}

No primeiro sábado, dia 01 de julho de 2017, participaram quarenta e três pessoas, sendo trinta e quatro delas alunos do CLF, sete professores e dois externos à instituição. Dos presentes, vinte e nove deles responderam ao questionário.

O Tabela 2 mostra os conteúdos que foram abordados durante a aula do dia 01 de julho de 2017. Nele se evidenciam os diferentes tópicos contemplados durante a exposição.

Analisando o Tabela 2, percebe-se a dimensão que a aula ganhou a partir do seu tema gerador. A exposição realizada pelos alunos motivou uma discussão que foi capaz de envolver todo o grupo de professores e as abordagens perpassaram suas disciplinas gerando um ambiente interdisciplinar, o que possui grande importân- cia no ensino, como sugerem os autores Grillo e Perez (2016). A Figura 1 a seguir é um registro dos participantes da aula planejada para o sábado letivo em questão e, como pode ser visto, o ambiente utilizado foi um auditório, pois era esperado um público bastante numeroso, uma vez que a aula tinha sido planejada de modo a envolver alunos de praticamente todos os semestres correntes do CLF em questão.

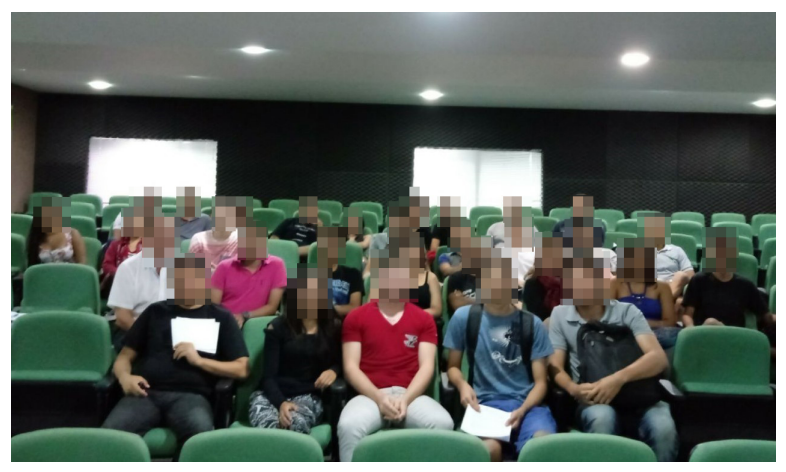

Figura 1: Participantes do primeiro sábado letivo de 2017.1.

Fonte: Créditos dos autores.

A seguir faz-se uma análise das respostas dadas pelos participantes aos questionários aplicados no final de cada momento de aprendizagem, sendo eles estruturados com cinco perguntas e um espaço para observações e sugestões, seis perguntas e três perguntas, respectivamente, seguindo ordem cronológica dos encontros.

\subsection{Análise do questionário aplicado no primeiro dia}

Em resposta à primeira pergunta (Como você classifica a temática do encontro?), uma pessoa classificou a temática como regular, sete pessoas, como boa e vinte e uma classificaram-na como excelente. $\mathrm{O}$ resultado além de constatar a importância da abordagem de temas que contextualizem o enredo no qual os estudantes estão inseridos, mostra a necessidade de o professor diversificar as abordagens uma vez que o seu público chega à sala de aula com diferentes desejos e perspectivas de aprendizagem.

Na segunda pergunta, buscou-se sondar dos envolvidos suas percepções da aula (a abordagem propriamente dita). Em resposta, quatro alunos julgaram que a aula não se diferenciava das demais; destes, um foi o aluno que no item anterior considerou a temática regular, dois estavam entre aqueles que a classificaram como boa, e um foi o que a julgou excelente, já vinte e cinco deles julgaram que a abordagem se diferenci- 
- Radioatividade

- A vida e o trabalho científico de Marie Curie

- A pesquisa científica e o método científico

- A reserva de Urânio de Itataia em Santa Quitéria

- Inovações tecnológicas

- Consciência científica e política

- A ética corporativa no consórcio Santa Quitéria

- Estratégias didáticas para o Ensino de Física

- Utilização dos recursos didáticos

- Interdisciplinaridade frente ao contexto social, político e econômico

- Comunicação e Linguagem: impactos da exploração do Urârio

- O currículo do Ensino Médio

- Estratégias para inserção do tema Radioatividade no Ensino Fundamental e Médio

- Modelagem matemática na Física: gráficos, tabulações e fórmulas algébricas.

Fonte: Créditos dos autores

ava da abordagem comumente vivenciada durante as disciplinas do curso. Analisando as falas, percebemos, da parte dos alunos, a valorização dos conceitos introduzidos dentro das discussões, frequentemente postos como 'esclarecedores' ou algo equivalente. Para $\mathrm{Ri}-$ cardo (2010):

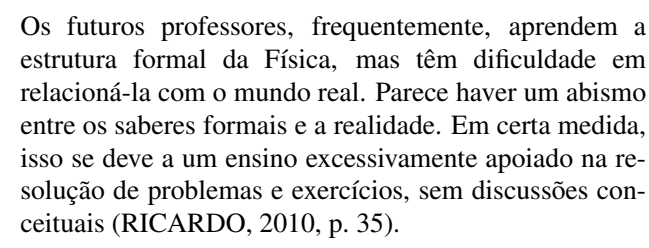

Os futuros professores, frequentemente, aprendem a estrutura formal da Física, mas têm dificuldade em relacioná-la com o mundo real. Parece haver um abismo entre os saberes formais e a realidade. Em certa medida, isso se deve a um ensino excessivamente apoiado na resolução de problemas e exercícios, sem discussões conceituais (RICARDO 2010 p. 35).

A abordagem do conteúdo foi concretizada por uma exposição oral mediada pela apresentação de imagens (figuras, mapas, entre outros) e vídeos executados por dois alunos e um monitor da disciplina de Metodologia do Ensino de Física (MEF), sendo mediada por interlocuções de professores do curso, das áreas de Física e Pedagogia. Além de uma excelente oportunidade para os alunos de diversos semestres interagirem, a aula possibilitou aos discentes da disciplina de MEF praticarem uma das estratégias metodológicas apropriadas por eles durante a disciplina. Diante das discussões, usar o contexto local para discutir aspectos de Física Nuclear mostrou-se uma excelente oportunidade para inserção desse conteúdo no Ensino Básico.

A terceira pergunta procurou saber deles se a aula tinha lhes possibilitado aquisição de conhecimentos extracurriculares. Somente o aluno que achou a temática regular considerou que não, os vinte e oito restantes afirmaram que os conhecimentos adquiridos naquela aula específica agregaram informações e conhecimentos adicionais ao currículo do Ensino Médio e ao até então adquirido na Licenciatura.

Em resposta à quarta pergunta (A abordagem gerou motivação para estudos subseqüentes?), dois dos questionados afirmaram não terem adquirido motivação para estudos posteriores, sendo que um deles julgou a temática regular e o outro, boa, ao passo que vinte e sete deles afirmaram terem saído do encontro motivados para estudos subsequentes.

$\mathrm{Na}$ quinta pergunta do questionário indagou-se aos envolvidos, no decurso da exposição, se eles perceberam a interação entre as diferentes turmas e professores durante a aula. Dos vinte e nove alunos respondentes, vinte e oito afirmaram que sim, que a forma com que a aula foi conduzida permitiu interações entre os alunos das diferentes turmas e os professores, e permitiu também um diálogo interdisciplinar entre eles. Para Fazenda (2008) ao tratarmos de abordagens interdisciplinares durante a formação de professores, cabe pensar aspectos que envolvem a cultura do lugar onde sua formação ocorre. Neste contexto, aliar o tema Radioatividade à discussão da construção da mina de Itataia, dentro da aula do sábado letivo, possibilitou trazer os alunos para centro da discussão, e nela, realizar análises sob a perspectiva de diferentes disciplinas do CLF.

Em seguida, questionou-se se os envolvidos já tinham conhecimento prévio da temática abordada na aula em foco. Ao se analisar as respostas, percebeu-se que nove alunos não haviam escutado falar nem da reserva de Urânio em Santa Quitéria nem da cientista Marie Curie, muito menos ainda estudado tópicos de Física 
Nuclear; já seis dos questionados afirmaram ter conhecimento prévio sobre a temática pois haviam estudado tal conteúdo nas aulas de Geografia do Ensino Médio; sete tinham conhecimento mas não o teriam obtido por intermédio da escola e sim por meio de jornais, internet, leituras de artigos científicos, entre outros. Os demais se abstiveram de responder a esse questionamento.

Por fim, foi solicitado que fizessem seus comentários sobre as aulas e eles se limitaram a elogiar o desempenho dos alunos palestrantes que, segundo eles, conduziram muito bem a aula, e a sugerir uma maior divulgação nas próximas vezes que esse tipo de aula for programada. A maior divulgação a que se referem os alunos diz respeito à inclusão de mais turmas nas atividades, fato que não se tornou possível devido ao dia da aula e à grande distância do campus para a residência dos professores, como foi descrito na Introdução deste trabalho.

\subsection{Análise do questionário aplicado no segundo dia}

No sábado letivo do dia 08 de julho de 2017 participaram cinquenta e três pessoas, dentre elas, quarenta e três alunos do CLF, sete professores e três participantes externos que se interessaram pela temática abordada (Figura 2).

Novamente se questionou os alunos participantes sobre a temática do encontro e oito deles responderam considerar a temática boa, enquanto quinze atestaramna como excelente, sendo que trinta dos presentes não devolveram o questionário. O elevado número de abstenções se justifica pelo fato de que, devido à dificuldade de transporte, a maioria dos alunos não retornou no turno da tarde, quando foram distribuídos os questionários.

$\mathrm{Na}$ segunda pergunta buscou-se sondar o semestre dos alunos participantes (qual semestre você cursa?). A análise das respostas mostrou que cinco deles cursavam disciplinas do segundo semestre, nove do terceiro semestre, três do quarto semestre, dois do sétimo, dois eram graduados em Física, um era aluno do oitavo semestre e um não cursava Licenciatura em Física. O envolvimento majoritário se deu no segundo e terceiro semestres, possivelmente devido ao maior envolvimento dos professores, aliado ao fato de que são turmas mais numerosas. A Figura 2 faz parte do registro fotográfico deste sábado letivo e foi depositada nos arquivos da instituição. Quando comparada à Figura 1, pode-se perceber um público mais numeroso (10 participantes a mais do que o anterior).

A terceira pergunta procurou averiguar o que os

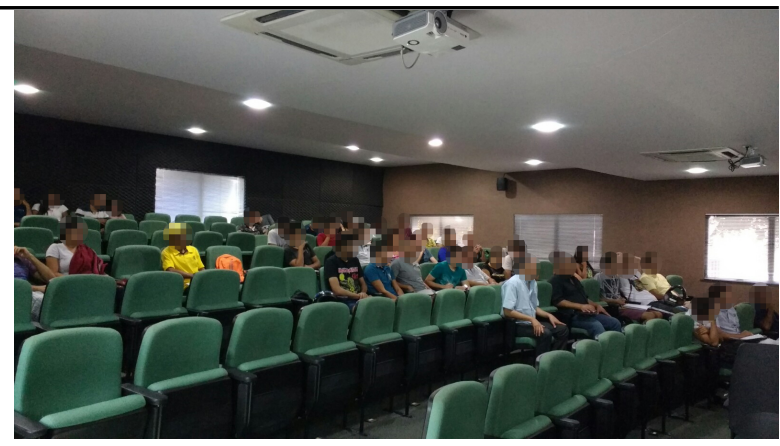

Figura 2: Participantes no segundo sábado letivo de 2017.1. Fonte: Créditos dos autores.

envolvidos acharam da aula (abordagem propriamente dita). Ao todo, doze pessoas julgaram-na como boa e onze classificaram-na como excelente. Esses resultados mostram a viabilidade do conteúdo considerado, a partir do terceiro semestre do Curso de Licenciatura em Física, uma vez que a sua aprovação de certa forma revela, por parte dos alunos, uma parcela favorável de compreensão.

A quarta pergunta se deteve novamente sobre a questão da motivação para estudos posteriores (A abordagem gerou motivação para estudos subseqüentes?). Desta vez, vinte e um dos respondentes afirmaram que se sentiam motivados para retornar a estudos da temática focada em situações posteriores, e dois deles disseram que embora a aula tenha sido boa, ela não despertou neles o desejo para estudos e pesquisas subsequentes. Observou-se pelas respostas abertas, legitimadas no contato direto com os alunos, que as exposições consideradas mais motivadoras e também as mais proeminentes na memória do grupo foram justamente aquelas mediadas por professores mais experientes e que procuraram orientar pragmaticamente os debates, o que corrobora com o pensamento de Santos (2007, p. 5): “A simples inclusão de questões do cotidiano pode não implicar a discussão de aspectos relevantes para a formação do aluno enquanto cidadão ou não motivar suficientemente os alunos para se interessar por ciências."

$\mathrm{Na}$ quinta pergunta questionou-se aos envolvidos se o conteúdo estudado poderia ser útil em outras áreas do conhecimento. Todos os participantes responderam que sim. Isso mostra que eles perceberam, a partir da abordagem feita, que as oscilações não constituem um fenômeno exclusivo da Física. Durante a exposição feita pelo professor convidado, com intervenções de um professor do curso, procurou-se mostrar que o modelamento matemático e as analogias aos sistemas físicos 
podem ser empregados para descrever fenômenos de outras áreas do conhecimento. Além disso, foram apresentadas aplicações em contextos distintos abrangendo algumas áreas do conhecimento humano como Biologia, Biofísica, Economia e Astrofísica na intenção de que o tratamento dado fosse ao mesmo tempo contextualizado e interdisciplinar.

Por fim, a sexta pergunta tencionou investigar as principais dificuldades enfrentadas pelos alunos para participar dos sábados letivos ( $O$ que dificulta ou inviabiliza sua presença nas aulas durante os sábados letivos?). No que diz respeito às principais dificuldades enfrentadas pelo corpo de alunos quanto à sua participação nos sábados letivos, eles destacaram que:

- O transporte escolar gratuito (administrado pelos municípios) está indisponível nos finais de semana;

- A distância entre o campus e as suas residências é por demais acentuada (o que corresponde à maioria absoluta dos casos);

- Os alunos geralmente trabalham, sendo que a sobrecarga de trabalho, aliada ao estudo semanal, compromete sua disposição para participar de atividades letivas aos sábados;

- O restaurante acadêmico não abre nos sábados;

A sobrecarga de estudo e trabalho mostrou-se um obstáculo à participação dos alunos nas aulas durante os sábados letivos, uma vez que parte dos discentes chega ao final de semana com grande fadiga, física e mental. $\mathrm{Na}$ fala a seguir, obtida como resposta à sexta pergunta do questionário, é possível perceber a realidade vivenciada por alguns discentes e que, além de inviabilizar sua participação nas atividades complementares que ocorrem nos contraturnos ou em finais de semana, como palestras, seminários, oficinas e aulas de campo, comprometem sua formação geral, uma vez que tais atividades encerram, em si, elementos formativos diferenciados.

“Após sair da faculdade trabalho na pizzaria até as $2 \mathrm{~h}$ horas da manhã e no sábado trabalho pela manhã em uma loja e na pizzaria das $15 \mathrm{~h}$ às $2 \mathrm{~h}$."

Fala de um aluno do curso

\subsection{Análise do questionário aplicado no terceiro dia}

No dia 05 de agosto de 2017 foi concluída a proposta de aulas para os sábados letivos 2017.1. Na ocasião, professores e alunos do CLF realizaram uma visita monitorada à Casa do Capitão-Mor e ao Museu MADI em Sobral-CE. Tal visita propiciou uma oportunidade para enriquecimento cultural dos alunos participantes e oportunizou momentos para discussões contextualizadas e interdisciplinares. Na Casa do Capitão-Mor os estudantes tiveram aula de história regional e, no final dela, presenciaram interlocuções entre professores, o que possibilitou aos envolvidos perceber que áreas como História, Paleontologia e Física se fizeram essenciais no resgate histórico que tornou possível a existência da casa, local que se constitui como um dos principais monumentos históricos da cidade de Sobral, essencial para preservação da memória dos acontecimentos que deram origem à atual cidade. A citação a seguir é um recorte da fala do professor de Física e retrata parte das interlocuções realizadas pelos professores e alunos logo após o encerramento da fala do professor de História.

[...] Conforme a fala do historiador, ao se propor estudar
o local e resgatar a memória do período que teve ori-
gem a cidade, ele precisou da ajuda de um arqueólogo,
o qual se valeu de técnicas como a Luminescência para
datação de objetos encontrados na escavação do local.
Percebam com isso, que não é possível fazer ciência se-
paradamente, isto é, com tratamentos compartimentados
de conteúdos! Vocês enquanto professores irão trabalhar
com a Física ao mesmo tempo em que professores de ou-
tras áreas estarão trabalhando suas disciplinas, é preciso
então que haja um planejamento coletivo de forma que
os conteúdos sejam tratados paralelamente, mas que os
estudantes percebam suas inter-relações (Fala do pro-
fessor de Física).

Durante as falas dos professores, os alunos faziam interferências no sentido de expor suas dúvidas ou acrescentar informações que consideravam pertinentes. Na Figura 3 pode-se observar os participantes do terceiro sábado letivo durante a visita a Casa do CapitãoMor.

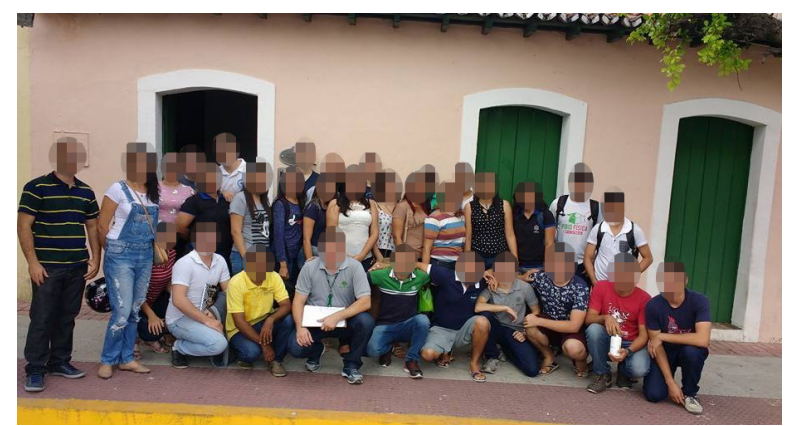

Figura 3: Participantes do terceiro sábado letivo de 2017.1. Fonte: Créditos dos autores. 
Participaram desse momento trinta e seis pessoas, sendo trinta alunos do curso de Licenciatura em Física, cinco professores e um participante externo. A imagem ilustrada na Figura 3 mostra alunos e professores reunidos em frente à Casa do Capitão-Mor, onde foi realizado o primeiro momento da aula proposta.

O questionário investigativo e avaliativo do último dia foi respondido por 23 (vinte e três) deles. A primeira pergunta buscou saber seus interesses quanto ao tipo de aula (Como você julga a proposta de aula de campo com visitação a Casa do Capitão-Mor e ao museu MADI?). Em resposta, $74 \%$ deles afirmaram que a proposta foi excelente e $26 \%$ consideram-na boa.

A pergunta seguinte indagou se eles se disporiam a promover aulas do mesmo tipo com seus alunos ou com futuros alunos. A resposta foi unânime, $100 \%$ dos respondentes afirmaram que sim e justificaram que:

Aulas de campo enriquecem e estimulam os alunos.

Para estimular a aprendizagem e fugir do tradicionalismo.

\section{A formação cultural é de grande utilidade.}

Falas de alunos

Por fim, a terceira pergunta buscou investigar que outros lugares seriam de interesse deles e quais disciplinas e conteúdos seriam possíveis de envolver. As respostas indicam locais como o Museu do Eclipse de Sobral, a biblioteca municipal, o Museu Dom José, a gruta de Ubajara, Sítio do Bosco, Museu da Cachaça, a Fábrica de Cimento da região e a jazida de urânio em Santa Quitéria. Eles apontaram que disciplinas como História, Física e Geografia poderiam ser abordadas em alguns desses lugares, entretanto não especificaram os conteúdos que poderiam ser trabalhados. O fato é que carecemos de propostas que visem à concretização de abordagens contextualizadas e interdisciplinares e que os estudantes, apesar de apreciarem esse tipo de estratégia pedagógica, e aparentemente pela carência de sua realização, apresentam uma grande dificuldade em sugerir possíveis programas capazes de extrapolar a exploração da fenomenologia pura.

A Tabela 3 inclui os dados referentes à temporada de sábados letivos do semestre 2016.2. Nela foi proposta a elaboração de questões pelos alunos do CLF, sendo estas relativas aos conteúdos ministrados no respectivo período. Após esse momento, as questões elaboradas pelos discentes foram discutidas em grupo e reavaliadas a partir das contribuições dos professores cujas áreas estão listadas a seguir. Concluído esse momento, os alunos foram instruídos pelos professores sobre como elaborar um plano de aula e executá-lo de modo a expor o conteúdo e resolver as cinco questões selecionadas dentre aquelas formuladas por eles (todas as questões elaboradas deveriam contextualizar alguma situação física vivenciada por eles no cotidiano ou representadas em filmes).

$\mathrm{Na}$ Tabela 3 pode-se observar que houve uma freqüência média de participação dos alunos de $15 \%$, o que representa um percentual muito baixo tendo em vista o universo de alunos. Já com relação aos professores, percebe-se que apenas $50 \%$ deles participaram da execução das atividades propostas para os sábados letivos do semestre de 2016.2. Convém destacar que, em períodos anteriores a 2016.2, as aulas foram programadas por disciplinas, isto é, sem o enfoque da interdisciplinaridade, havendo um envolvimento de apenas $8 \%$ dos alunos nas atividades propostas e $16 \%$ dos docentes na execução de atividades nestes dias. Isso mostra que propostas que envolvam interação entre as áreas do conhecimento e levem a uma aprendizagem contextualizada e interdisciplinar têm um maior potencial de envolvimento.

A seguir podem-se observar, na Tabela 4, dados referentes às atividades desenvolvidas durante o primeiro semestre letivo de 2017, que podem ser confrontados com os da Tabela 3 e demais informações.

$\mathrm{Na}$ Tabela 4 evidencia-se uma participação de $25 \%$ dos estudantes nas atividades programadas para os sábados letivos do semestre de 2017.2. Isso representa um aumento percentual de $10 \%$ dos alunos em relação ao semestre anterior e de $17 \%$ em relação ao período anterior a 2016.2. Já com relação ao número de professores participantes, observa-se que o número de envolvidos se manteve constante do período de 2016.2 para 2017.1. Uma justificativa para o fato está certamente ligada à distância física entre as residências dos docentes e seu local de trabalho.

\section{CONCLUSÕES}

Acredita-se que a estratégia proposta concretizou um importante momento na formação dos licenciandos em Física ao permitir aos acadêmicos e aos docentes do CLF pensar de forma integrada conhecimentos que, por tradições históricas, vêm sendo muitas vezes ensinados sem demonstrarem inter-relações mútuas. Além disso, trabalhar numa perspectiva de contextualização e interdisciplinaridade requereu dos professores um maior envolvimento a ponto de eles considerarem, numa discus- 
CONTEXTUALIZAÇÃO E INTERDICIPLINARIDADE NUM CURSO DE LICENCIATURA EM FÍSICA: UMA EXPERIÊNCIA VIVENCIADA NO IFCE CAMPUS SOBRAL

Tabela 3: Dados do último período de sábados letivos institucionais de 2016.

\begin{tabular}{|c|c|c|c|}
\hline \multirow{2}{*}{ No DE ALUNOS MATRICULADOS } & \multicolumn{3}{|c|}{ NÚMEROS DE ALUNOS PRESENTES } \\
\hline & DIA 25/06/2016 & DIA 02/07/2016 & DIA 18/07/2016 \\
\hline 130 & 21 & 18 & 20 \\
\hline $\mathrm{N}^{0}$ DE PROFESSORES PRESENTES & \multicolumn{3}{|c|}{$\begin{array}{c}\text { NÚMEROS DE PROFESSORES PARTICIPANTES } \\
\text { NA CONCRETIZAÇÃO }\end{array}$} \\
\hline NO PLANEJA & DIA $25 / 06 / 2016$ & DIA 02/07/2016 & DIA 18/07/2016 \\
\hline 12 & 6 & 6 & 6 \\
\hline ÁREAS DO CONHECIMENTO QUE & DIA $25 / 06 / 2016$ & DIA 02/07/2016 & DIA 18/07/2016 \\
\hline $\begin{array}{l}\text { INTERAGIRAM NA CONCRETIZAÇÃO } \\
\text { DA PROPOSTA }\end{array}$ & $\begin{array}{l}\text { - FÍSICA } \\
\text { - PEDAGOGIA } \\
\text { - MATEMÁTICA }\end{array}$ & $\begin{array}{l}\text { - FÍSICA } \\
\text { - PEDAGOGIA } \\
\text { - MATEMÁTICA }\end{array}$ & $\begin{array}{l}\text { - FÍSICA } \\
\text { - PEDAGOGIA } \\
\text { - MATEMÁTICA }\end{array}$ \\
\hline
\end{tabular}

Fonte: Elaborada pelos autores.

Tabela 4: Dados do último período de sábados letivos institucionais de 2017.

\begin{tabular}{|c|c|c|c|}
\hline \multirow{2}{*}{ No DE ALUNOS MATRICULADOS } & \multicolumn{3}{|c|}{ NÚMEROS DE ALUNOS PRESENTES } \\
\hline & DIA 01/07/2017 & DIA 08/07/2017 & DIA 05/08/2017 \\
\hline 141 & 34 & 43 & 30 \\
\hline No DE PROFESSORES PRESENTES & \multicolumn{3}{|c|}{$\begin{array}{c}\text { NÚMEROS DE PROFESSORES PARTICIPANTES } \\
\text { NA CONCRETIZAÇÃO }\end{array}$} \\
\hline NO PLANEJAMENTO & DIA 01/07 & DIA 08/07 & DIA 05/08 \\
\hline 12 & 7 & 6 & 5 \\
\hline & DIA 01/07 & DIA 08/07 & DIA 05/08 \\
\hline $\begin{array}{c}\text { ÁREAS DO CONHECIMENTO QUE } \\
\text { INTERAGIRAM NA CONCRETIZAÇÃO } \\
\text { DA PROPOSTA }\end{array}$ & $\begin{array}{l}\text { - FÍSICA } \\
\text { - PEDAGOGIA } \\
\text { - MATEMÁTICA }\end{array}$ & $\begin{array}{l}\text { - FÍSICA } \\
\text { - PEDAGOGIA } \\
\text { - MATEMÁTICA }\end{array}$ & $\begin{array}{l}\text { - FÍSICA } \\
\text { - PEDAGOGIA } \\
\text { - MATEMÁTICA } \\
\text { - HISTÓRIA } \\
\text { - ARTES }\end{array}$ \\
\hline
\end{tabular}

Fonte: Elaborada pelos autores.

são geral de um dado problema, aspectos relacionados ao social, político, econômico, cultural, ético e ambiental, focando como orienta Carneiro e Moura (2016), um viés reflexivo e midiatizador do processo de ensino e aprendizagem.

Tendo em vista o número de participantes no primeiro semestre de 2017 (25\% dos alunos) confrontado com dados de sábados letivos anteriores (8\% em 2016.1 e $15 \%$ em 2016.2), confirma-se o fato de que uma aula contextualizada e interdisciplinar é capaz de motivar o aluno a estar em sala de aula, mesmo em se tratando de um dia de final de semana, no qual as formas de acesso ao campus são bem limitadas e envolvem gastos/investimentos do aluno, uma vez que os transportes municipais rodam somente nos dias da semana.

A pesquisa realizada mediante a aplicação dos questionários mostra que a temática abordada agradou à maioria dos alunos, ao passo que a metodologia adotada agregou valores positivos, a exemplo da aquisição de novos conhecimentos, valores culturais e a motivação para pesquisa. Tais resultados confirmam a fala de Zen e Pereira (2013), quando esses autores destacam a importância de atividades contextualizadas para resgatar o interesse dos alunos e ajudar na aprendizagem deles.

Discutir o tema Radioatividade e o problema da extração de urânio em Santa Quitéria sob as perspectivas de áreas diferentes, possibilitou aos estudantes a percepção de que as disciplinas não são compartimentadas, mas um conjunto de saberes cujos olhares se entrelaçam e se complementam numa análise amplificada do problema. Por outro lado, disciplinas como Políticas Educacionais, Comunicação e Linguagem, Ética e Currículos e Programas, que pertencem à área pedagó- 
gica, na visão dos alunos, ganharam mais significado de existência dentro do currículo da licenciatura, uma vez que seus conhecimentos mostraram relacionar-se diretamente a disciplinas específicas durante a discussão de um problema prático, que para eles, até então, era exclusivo da Física Moderna e Contemporânea.

A abordagem da temática Radioatividade, vida e obra de Marie Curie e a reserva de Urânio de Itataia mostrou-se uma excelente estratégia para implementar a temática Radioatividade no Ensino Básico. Além disso, segundo relatos de alunos, o problema da extração de Urânio em Santa Quitéria chegou a eles por meio das aulas de Geografia, não das de Física, o que aponta para o fato de que tal conteúdo, embora seja um assunto presente nas discussões da região, não está sendo ensinado na disciplina de Física dos ensinos Fundamental e Médio.

Trabalhos futuros poderão abordar propostas interdisciplinares para tratar da mesma temática nas aulas do Fundamental e Médio, viabilizando a interação dos alunos com os professores de Física e Química, conforme indicam Pires e Messeder (2017). Além da Física e da Química, ao nível de Ensino Básico, podem ser agregadas as disciplinas de Biologia e Geografia, por exemplo, na discussão da temática Radioatividade, que se mostra tão relevante e atual, principalmente para o estado do Ceará, tendo em vista a proposta de construção para 2020 do complexo de exploração de urânio e fosfato em Santa Quitéria-CE.

Embora se tenha conseguido aumentar o número de participantes com a proposta de aula contextualizada e interdisciplinar, nota-se que aproximadamente $75 \%$ dos alunos do CLF, ainda sim, não frequentaram as atividades de sábado letivo e que, embora a nota técnica $n^{\circ}$ 11 de 2015 (IFCE, 2015) fale em agir com bom senso, prudência e moderação, de forma que se tomem atitudes levando-se em consideração a relação de proporcionalidade entre os meios empregados e a finalidade a ser alcançada, aulas durante os sábados, particularmente dentro de um contexto de migração pendular, são inevitavelmente pouco frequentadas por alunos e professores e, dadas as dificuldades reais de locomoção e alimentação, não cabe penalizá-los por isso. Por outro lado, também não cabe alijar os faltosos de atividades didaticamente relevantes e se, de fato, a finalidade do ato educativo é a excelência na formação do aluno de modo a promover seu desenvolvimento integral e colaborar com a sua inclusão no mercado de trabalho, os sábados letivos precisam ser repensados no sentido de se efetivar a sua democratização. Fica claro, então, que novos estudos precisam ser feitos no sentido de verificar as condições reais para a viabilidade dos sábados letivos institucionais, estudos capazes de apreender as realidades locais dos diferentes campi e revelar seus pontos nodais.

De acordo com a portaria $n^{0} 1.134$ de 2016 do Ministério da Educação (BRASIL, 2016c), instituições com o perfil dos Institutos Federais, que ofertam pelo menos um curso de graduação, poderão ofertar disciplinas na modalidade de Ensino a Distância (EAD), desde que a oferta não ultrapasse $20 \%$ (vinte por cento) da carga horária total do curso. Sendo assim, possíveis soluções para garantir a inclusão de alunos e professores podem passar pelo uso do contraturno, combinado com aulas em ambientes virtuais de aprendizagem na modalidade EAD, para a ministração de conteúdos e aplicação de avaliações. Ações como estas poderiam contribuir com o aumento da frequência dos estudantes e incrementar a sua participação, ajudando a mitigar o problema.

Embora a proposta em foco tenha sido concretizada em um momento extraordinário, abordagens que envolvam tratamentos contextualizados e interdisciplinares devem ser pensadas dentro dos currículos dos cursos de licenciatura, de modo a viabilizar propostas rotineiras que permitam maior interação dentro do grupo de docentes e, até mesmo, entre os alunos em seus variados semestres.

\section{REFERÊNCIAS}

ALMEIDA, M. d. S. G.; FERREIRA, P. R.; MORAES, F. F. de; BATISTA, N. J.; BALMACEDA, A. S. T. Possibilidades para pensar a educação física e seu caráter interdisciplinar. Revista Especial de Educação Física. Ed, v. 1, n. 2, p. 31-59, 2005.

BRASIL. Ceará, Santa Quitéria, infográficos: dados gerais do município. Censo de 2016. 2016. Ministério do Planejamento, Orçamento e Gestão. Disponível em: $<$ http://cidades.ibge.gov.br/painel/painel.php?lang= $\&$ codmun=231220\&search=cear\%E1|santa-quiteria $>$ Acesso em: 19 jul. 2017.

Ofício circular no 2 de 2016: Calendário de reposição de greve. 1 . ed. Brasília, 2016.

Portaria 1.134 de 10 de outubro de 2016.

Revoga a Portaria MEC no 4.059, de 10 de dezembro de 2004, e estabelece nova redação para o tema. 2016. Disponível em: <http: //www.ufrgs.br/sead/institucional/legislacao-ead-1/ documentos/portaria-1134-2016-mec > Acesso em: 23 out. 2018. 
CONTEXTUALIZAÇÃO E INTERDICIPLINARIDADE NUM CURSO DE LICENCIATURA EM FÍSICA: UMA EXPERIÊNCIA VIVENCIADA NO IFCE CAMPUS SOBRAL

CARNEIRO, C. C. B. E. S.; MOURA, F. M. T. Interdisciplinaridade e contextualização nos projetos políticos pedagógicos em cursos de formação inicial de professores de química. Revista Brasileira de Ensino de Ciência e Tecnologia, v. 9, n. 2, p. 78-92, 2016.

CARVALHO, A. M. P.; GIL-PéREZ, D. Formação de professores de Ciências: tendências e inovações. 10. ed. São Paulo: Cortez, 2011.

CHIQUETTO, M. J. O currículo de física do ensino médio no brasil: discussão retrospectiva. Revista e-curriculum, Pontifícia Universidade Católica de São Paulo, v. 7, n. 1, p. 1-16, 2011.

FAZENDA, I. O que é interdisciplinaridade? 1. ed. São Paulo: Cortez, 2008.

FERNANDES, C.; NASTACIO, P. Mina de Itataia terá exploração para 2020. Fortaleza: [s.n.], 2017. Portal C4 Notícias. Disponível em: <http://blogs.opovo.com.br/c4noticias/2017/06/26/ mina-de-itataia-tera-exploracao-para-2020/> Acesso em: 10 out. 2018.

GRILLO, M. L.; PEREZ, L. R. O violão no ensino de física. In: GRILLO, M. L.; PEREZ, L. R. (Ed.). Física e Música. São Paulo: Editora Livraria da Física, 2016. cap. 5, p. 61-76.

IFCE. Nota Técnica no 11: elaboração de calendário letivo do IFCE pós-greve, ano de referência 2015. Ceará, 2015. Pró-reitoria de Ensino. Disponível em: <https://proen.ifce.edu.br/projects/atos-normativos/ issues?query_id=48> Acesso em: 19 jul. 2017.

Nota Técnica $n^{0} 19$ retificada: Recomendações sobre elaboração de calendário acadêmico no IFCE, ano de referência 2016. Ceará, 2016. Pró-reitoria de Ensino. Disponível em: $<$ https://proen.ifce.edu.br/attachments/download/1745/ Nota\%20Informativa\%20019-2016-PROEN.pdf>. Acesso em: 26 jul. 2017.

LENSKI, R. E. Dynamics of interactions between bacteria and virulent bacteriophage. In: C., M. K. (Ed.). Advances in Microbial Ecology. Boston, MA: Springer, 1988. v. 10.

LIMA, M. E. C. d. C.; GERALDI, C. M. G.; GERALDI, J. W. O trabalho com narrativas na investigação em educação. Educação em revista, Directory of Open Access Journals, v. 31, n. 1, p. 17-44, 2015.
LINDE, A. Inflationary cosmology. Physics Reports, v. 333, n. 1, p. 575-591, 2000.

LOPES, S. ITATAIA: Para uns, desenvolvimento. Para outros, perigo. Fortaleza: [s.n.], 2014. O Estado. Disponível em: <http://www.oestadoce.com.br/cadernos/oev/ itataia-para-uns-desenvolvimento-para-outros-perigo > Acesso em: 10 out. 2018.

PIRES, T.; MESSEDER, J. Radioatividade e Educação Básica na Perspectivas dos documentos Oficiais. Gramado-RS: [s.n.], 2017. $57^{\circ}$ Congresso Brasileiro de Química. Disponível em: <http://www.abq.org.br/cbq/trabalhos_aceitos_ detalhes, 10912.html\#> Acesso em: 29 ago. 2017.

RICARDO, E. C. Problematização e contextualização no ensino de física. In: CARVALHO, A. M. P. (Ed.). Ensino de Física. 1. ed. São Paulo: Cengage Learning, 2010. cap. 2, p. 29-51.

ROMEO, F. A simple model of energy expenditure in human locomotion. Revista Brasileira de Ensino de Física, SciELO Brasil, v. 31, n. 4, p. 4306-4310, 2009.

SALAMAGA, M. An application of the harmonic oscillator model to verify dunning's theory of the economic growth. Statistika: Statistics and Economy Journal, Directory of Open Access Journals, v. 93, n. 3, p. 56-69, 2013.

SANTOS, W. L. P. Contextualização no ensino de ciências por meio de temas cts em uma perspectiva crítica. Ciência \& Ensino (ISSN 1980-8631), v. 1, n. número especial: "Educação em Ciência, Tecnologia, Sociedade e Ambiente", p. 1-12, 2007.

ZEN, C. R. L.; PEREIRA, R. F. A física do cotidiano: textos paradidáticos de calorimetria e termometria. Os desafios da escola pública paranaense na perspectiva do professor. Cadernos PDE. 2013. Versão online. Disponível em: <http://www.diaadiaeducacao.pr.gov.br/portals/ cadernospde/pdebusca/producoes_pde/2013/2013_ uem_fis_artigo_claudio_roberto_lopes_zem.pdf $>$. Acesso em: 03 abr. 2017. 